\title{
Surgical Evacuation of a Pontine Hematoma due to Rupture of a Capillary Telangiectasis in a Young Patient -Case Report-
}

\author{
Katsuzo KiYA, Tamotsu KiTAOKA, Masayuki NOMUrA, \\ Nobuyoshi SATO, Masashi NAITO* and Michiya OHTA** \\ Department of Neurosurgery, Hiroshima Prefectural Hospital, \\ Hiroshima; *Research Institute for Nuclear Medicine and Biology, \\ Hiroshima University, Hiroshima; ${ }^{* *}$ Department of Neurology, \\ Hiroshima Red Cross Hospital, Hiroshima
}

\begin{abstract}
A 17-year-old female presented with a small pontine hematoma considered as having arisen from rupture of a capillary telangiectasis. Vertebral angiography showed fenestration of the left distal vertebral artery without any vascular anomaly in the pons. Histological examination of the surgical specimen verified the presence of a capillary telangiectasis adjacent to the hematoma. Rupture of a capillary telangiectasis as the source of pontine hematoma is very rarely documented histologically in surviving patients.
\end{abstract}

Key words: capillary telangiectasis, pons, cerebral hemorrhage, vertebral artery, cerebral angiography

\section{Introduction}

Surgical evacuation of spontaneous pontine hematomas in children and young adults has been reported by a number of authors. ${ }^{1,2,6,10,11,16,18,21,24,29,30 !}$ However, evidence of a vascular malformation having ruptured into the pons has rarely been demonstrated in operated cases..$^{8.9 .19,21,22,24.30)}$ We treated a juvenile patient for subependymal hematoma of the pontine tegmentum, in which a capillary telangiectasis was present in the surgical specimen.

\section{Case Report}

A 17-year-old female experienced gradual onset of unsteady gait for 2 months preceding hospital admission. Vertigo, vomiting, and headache appeared suddenly, 2 weeks prior to admission. This vertigo was induced on the left lateral position. The degree of these symptoms were gradually improved.

On admission the patient was alert, although headache and vertigo remained. Neurological examination revealed lateral horizontal nystagmus on both sides and ataxic gait. A lumbar puncture produced clear, watery cerebrospinal fluid. Roentgenograms of the skull were normal. A computerized tomographic (CT) scan demonstrated a small, highdensity mass, approximately $1 \mathrm{~cm}$ in diameter, adjacent to the right side of the compressed fourth ventricle. Contrast enhancement was slight (Fig. 1). Left vertebral angiography revealed fenestration of the left distal vertebral artery, but other vascular anomalies and mass effect were not evident at the posterior fossa (Fig. 2).

We performed a bilateral suboccipital craniectomy. After lateral retraction of the cerebellar tonsils the vermis was split and the rhomboid fossa of the

Received May 29, 1985; Accepted February 14, 1986 Author's present address: K. Kiya, M.D., Department of Neurosurgery, Futami Central Hospital, Miyoshi, Hiroshima, Japan. 


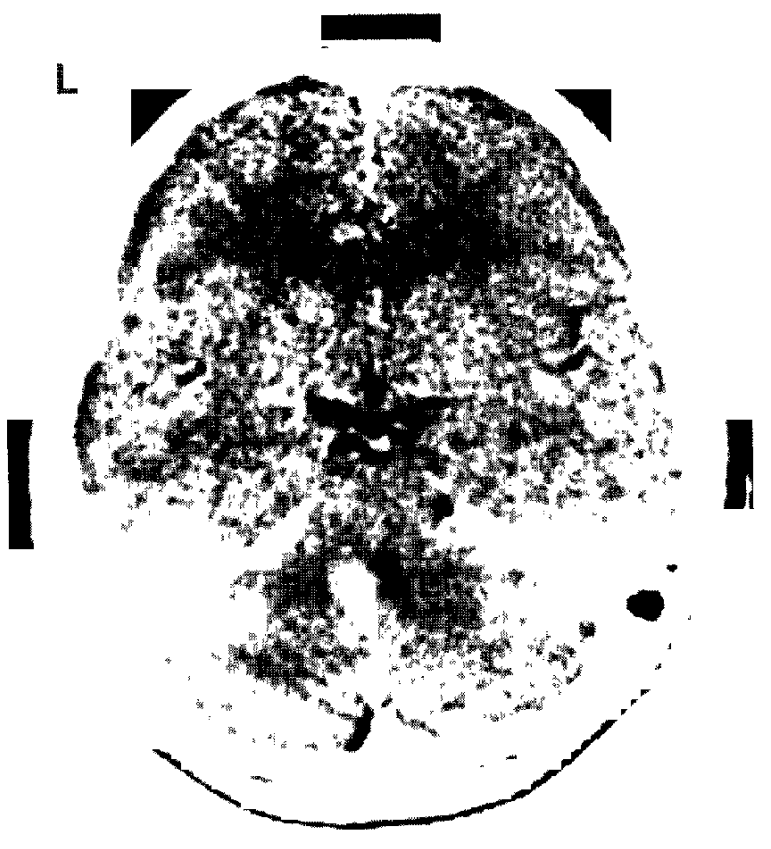

Fig. 1 Enhanced CT scan, showing a round, highdensity mass adjacent to the fourth ventricle.

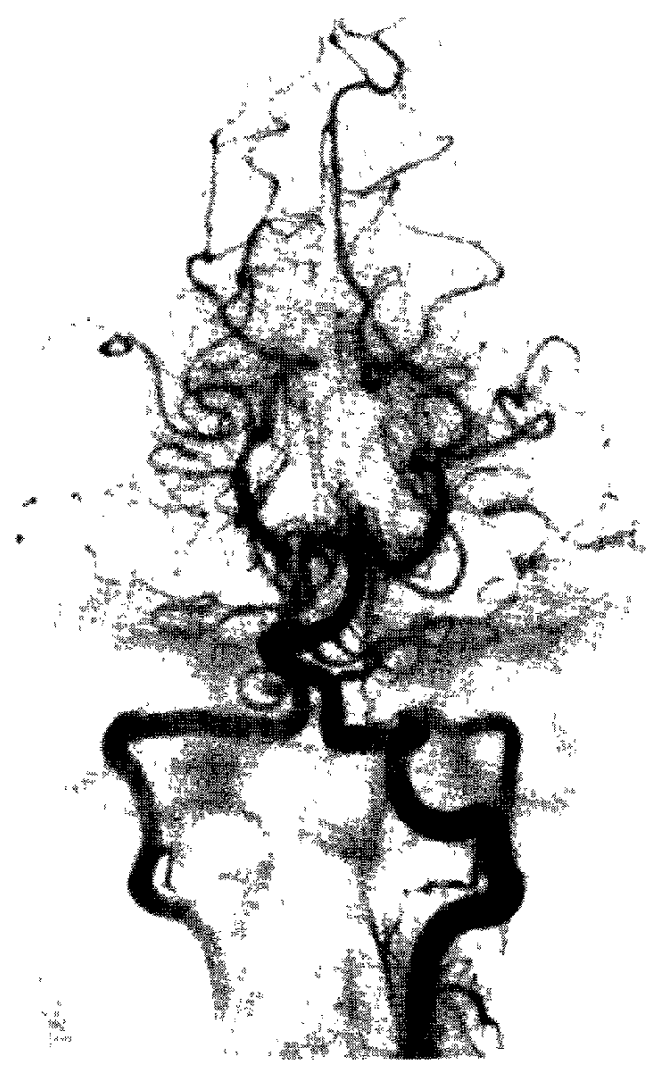

Fig. 2 Left vertebral angiogram, anteroposterior view in the arterial phase, revealing fenestration of the left distal vertebral artery.

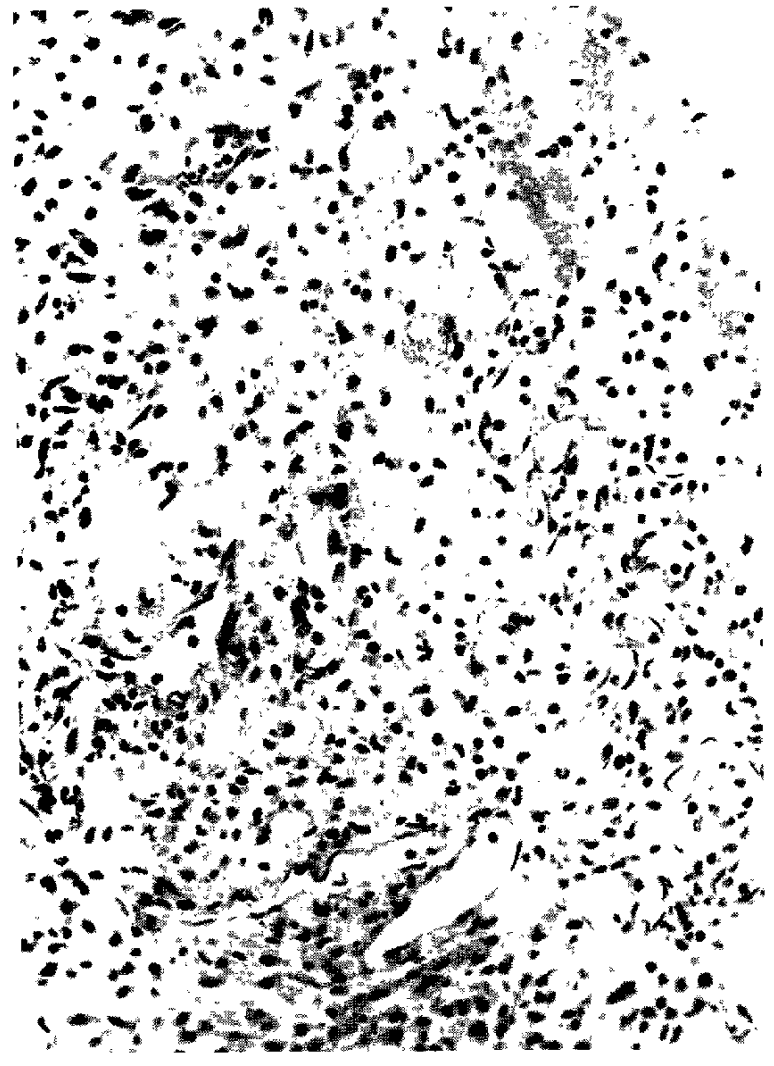

Fig. 3 Histological appearance of the surgical specimen, demonstrating abundant capillaries of varying diameter separated by inflammatory cells. HE stain, $\times 100$.

fourth ventricle came into view. A small, reddish, convex mass covered by the ventricular ependyma was visible at the right ventral corner of the fourth ventricle within the right pontine tegmentum. No abnormal vessels were seen around the mass. The ependymal layer was pulled away and a portion of the hemorrhagic tissue was removed.

The surgical specimen consisted of a massive hemorrhage with many small vessels, compatible with a capillary telangiectasis (Fig, 3). The capillary walls, which were thin and of varying diameter, were composed of typical, well-differentiated endothelial cells. The capillaries were separated by inflammatory, hemosiderin-laden cells.

The postoperative course was uneventful. Nystagmus, vertigo, and unsteady gait gradually improved, although these symptoms persisted to a mild degree. Two months after the operation the patient was able to attend school. A postoperative CT scan, on infusion of contrast material, demonstrated a residual high-density region, and a repeat $\mathrm{CT}$ scan revealed its persistence. However, by 8 months 
postoperatively it had disappeared completely.

\section{Discussion}

In the reported cases of surgically treated pontine hematomas, hemangiomatous tissue, ${ }^{30)}$ a cryptic angioma, ${ }^{211}$ a vascular malformation, ${ }^{221}$ and arteriovenous malformations ${ }^{9,19.24)}$ were histologically confirmed as the source of hemorrhage. However, a capillary telangiectasis has not previously been reported as a histologically documented cause of spontaneous pontine hematoma. Although it is known that capillary telangiectases are the most common vascular malformations in the pons, ${ }^{23)}$ their role in pontine hematoma is difficult to demonstrate because they are usually small and stable and the wall of the hematoma cavity may be destroyed by bleeding. In our case a specimen obtained from the clot and fibrin-containing tissue on the floor of the fourth ventricle was found to be a capillary telangiectasis that happened, by chance, to be adjacent to the clot.

There has been no report of a pontine capillary telangiectasis associated with fenestration of a vertebral artery. The incidence of fenestration in the distal vertebral artery varies between 0.23 and $1.90 \%,{ }^{5,12)}$ and is more frequent in Japan than in America and Europe..$^{57}$ There are some reports ${ }^{12,17)}$ of fenestration of the vertebral artery associated with congenital vascular anomalies, in particular with aneurysms and angiomas. It is interesting that in our case a capillary telangiectasis in the pons was associated with fenestration of the left distal vertebral artery.

Surgery for pontine hematomas is not performed routinely. In most of the operated cases of juvenile pontine hemorrhage, ${ }^{1,2,6,10,16,18,29,30)}$ brain tumor could not be ruled out before surgery. There are several reasons for the difficulty in diagnosis. The onset is not only sudden but also gradually progressive and symptoms tend to be recurrent. Vertebral angiography rarely demonstrates a vascular malformation. CT scans occasionally, over several months, reveal a high-density or heterogeneously dense mass in the pons. In cases of brain stem hematoma, Papo et al. ${ }^{201}$ mentioned that surgery is necessary in cases of intracranial hypertension caused by subependymal hematoma but that surgery is inappropriate for intra-axial hematomas. We operated on our patient because the CT findings were inconclusive; the high-density area seen on the CT scan might have been a brain tumor with a hematoma located in the right pontine tegmentum adjacent to the fourth ventricle.
Concerning the prognosis of capillary telangiectases within the pons, MacCormick et al. ${ }^{13)}$ stated that these appear to be the most innocuous type of angioma, for of 27 cases of pontine lesions, none was found to be associated with significant hemorrhage at autopsy. Russell and Rubinstein ${ }^{23)}$ pointed out that examination of quiescent capillary telangiectases provided no evidence of small antecedent hemorrhages, which is not the case with cavernous angiomas. On the other hand, there have been several reports $3.14,15,25,26,31)$ of postmortem findings of pontine hematomas resulting from rupture of capillary telangiectases. Prolonged and progressive neurological symptoms were present in these cases. According to these reports, capillary telangiectases apparently do not bleed easily. However, when a small hemorrhage arises from this type of angioma, as in the case reported here, it is uncertain whether or not rebleeding will occur in future which was reported in cases ${ }^{2,4,21)}$ with juvenile pontine hematoma secondary to rupture from other angiomas. In our patient, the contrast-enhanced, high-density area in the pons disappeared from the CT scan 8 months after surgery. It has not reappeared, nor have there been any new symptoms. The vertigo this patient experience initially on the left lateral position is typical MPPV (malignant persistent positional vertigo), ${ }^{27,281}$ due to hemorrhage in the right juxtarestiform body. ${ }^{7}$

\section{References}

1) Abroms IF, Yessayan L, Shillito J, Barlow CF: Spontaneous intracerebral haemorrhage in patients suspected of multiple sclerosis. $J$ Neurol Neurosurg Psychiatry 34: 157-162, 1971

2) Albright AL, Byrd RP, Harrison ML: Angiographically cryptic AVM presenting as a pontine tumor. Case report. I Neurosurg 53: 846-848, 1980

3) Antoni N: Vier Fälle seltenerer Gefässgeschwülste des Zentralnervensystems. Acta Chir Scand 85: 7-24, 1941

4) Bergman PS: Hemangioma of the pons. Case report and review of the literature. J Mount Sinai Hosp NY 17: 119-131, 1950

5) Carella A, Lamberti P, Federico F, Andreula CF: Double fenestration of the extracranial vertebral artery. Neuroradiology 15: 193-194, 1978

6) Doczi T, Thomas DGT: Successful removal of an intrapontine haematoma. $J$ Neurol Neurosurg Psychiatry 42: 1058-1061, 1979

7) Goto N, Hoshino T, Kaneko M, Ishikawa H: Central positional vertigo. Clinico-anatomic study. Neurol Med Chir (Tokyo) 23: 534-540, 1983

8) Inoue $Y$, Sato O: Successful removal of pontine haematoma due to rupture of cryptic arteriovenous 
malformation. Case report. Acta Neurochir (Wien) 69: 69-75, 1983

9) Kasai N, Fujiwara S, Yoshimoto T, Suzuki J: "Cryptic" arteriovenous malformation of the brain stem. A successfully operated case. No Shinkei Geka 9: 11611165,1981 (in Japanese)

10) Kohno $T$, Tsuda $T$, Nakagawa $Y$, Sogabe K, Matsumoto K: A juvenile case of spontaneous hemorrhage in the dorsal pontine area. No Shinkei Geka 10: 1097-1103, 1982 (in Japanese)

11) Koos WT, Sunder-Plassmann M, Salah S: Successful removal of a large intrapontine hematoma. Case report. J Neurosurg 31: 690-694, 1969

12) Kowada M, Yamaguchi K, Takahashi H: Fenestration of the vertebral artery with a review of 23 cases in Japan. Neuroradiology 103: 343-346, 1972

13) MacCormick WF, Hardman JM, Boulter TR: Vascular malformation ("angiomas") of the brain, with special reference to those occurring in the posterior fossa. $J$ Neurosurg 28: 241-251, 1968

14) Marcus A: Tumorsymptome bei einigen Erkankungen in Pons- und Oblongata-Gebiets. Folia Neuropathologica Estoniana 3: 433-443, 1925

15) Michael JC, Levin PM: Multiple telangiectases of the brain. A discussion of hereditary factors in their development. Arch Neurol Psychiat 36: 514-529, 1936

16) Miyahara $S$, Ohta $H$, Takaki $T$, Yonemasu $Y$, Yokota K: Recurrent pontine hemorrhage associated with persistent primitive trigeminal artery and facial angioma. No To Shinkei 29: 685-689, 1977 (in Japanese)

17) Mizukami M, Mine T, Tomita T: Window formation of vertebral artery (vertebral diastematoarteria). On the association with cerebral aneurysm and/or arteriovenous malformation. No To Shinkei 20: 1271-1276, 1968 (in Japanese)

18) Obrador S, Dierssin G, Odoriz BJ: Surgical evacuation of a pontine-medullary hematoma. Case report. $J$ Neurosurg 33: 82-84, 1970

19) Ochiai C, Sano K, Kobayashi S, Sasaki T, Mayanagi $Y$ : Clinical study of pontine hemorrhage with special reference to CT classification and surgical indication. No To Shinkei 31: 803-811, 1979 (in Japanese)
20) Papo I, Pasquini U, Salvolini U: Subependymal brainstem hematomas: A report of two cases. Neuroradiology 11: 279-282, 1976

21) Pau A, Viale ES, Turtas S: Surgical removal of a pontine haematoma associated with a cryptic angioma. Case report. Acta Neurochir (Wien) 50: 299-303, 1979

22) Pouyanne MH, Got M, Julien J, Riemens V, Paoli M: Deux cas d'hématomes intraprotubérantiels opérés. Étude critique. Neurochirurgie 13: 738-742, 1967

23) Russell DS, Rubinstein LJ: Pathology of Tumours of the Nervous System, ed 4. London, Edward Arnold, 1977, pp 128-129

24) Scott BB, Seeger JF, Schneider RC: Successful evacuation of a pontine hematoma secondary to rupture of a pathologically diagnosed "cryptic" vascular malformation. Case report. I Neurosurg 39: 104108,1973

25) Sjövall E, Lundgren N: Zur Kenntnis des Angioma simplex cerebri (Telangiectasien). Acta Path Microbiol Scand [Suppl] 37: 476-492, 1938

26) Teilmann K: Hemangiomas of the pons. Arch Neurol Psychiat 69: 208-223, 1953

27) Uemura K: Vertigo from neurosurgical standpoint. Chiryo 67: 1245-1252, 1985 (in Japanese)

28) Uemura $K$, Nozue $M$ : Approach to patients with vertigo. Their typical clinical pictures from neurosurgical standpoints. No Shinkei Geka 11: 229-242, 1983 (in Japanese)

29) Vaquero $\mathbf{J}$, Areitio E, Leunda G, Bravo G: Hematomas of the pons. Surg Neurol 14: 115-118, 1980

30) Verbiest H: Arteriovenous aneurysms of the posterior fossa. Progr Brain Res 30: 383-396, 1968

31) Zeller RS, Chutorian AM: Vascular malformations of the pons in children. Neurology (Minneap) 25: $776-780,1975$

Address reprint requests to: K. Kiya, M.D., Department of Neurosurgery, Futami Central Hospital, 650 Tohkaichi-cho, Miyoshi, Hiroshima 728, Japan. 